\title{
Pinch analysis, as a technique for optimising resource utilisation and promoting environmental sustainability: A review of recent case studies from the developing world and transition economies
}

\begin{abstract}
G Venkatesh
Abstract: Pinch analysis, as a technique to optimise the utilisation of resources, traces its beginnings to the 1970s in Switzerland and the UK ETH Zurich and Leeds University to be more precise. Over four decades down the line, this methodology has entrenched itself in research circles around the world. While the technique was developed, to begin with, for energy (heat) recovery, it has since then expanded to embrace several other fields, and enabled optimisation of resource utilisation in general. The motive behind this article is to perform a focused, selective review of recent case studies from the developing world and transition economies, having 'pinch analysis' in their titles and thereby as their 'core, crux and gist', during the period 2008-2018. The resources focused on, include heat energy, electrical energy, water, solid waste, money, time, land (surface area), storage space (volume), human resources, mass of resources in general and hydrogen, while a handful of publications have their focus on carbon dioxide (greenhouse gases in general) emissions. Multi-dimensional pinch analysis promises to be an effective tool for sustainability analysis in the years to come; most importantly in the developing world where social well-being and economic development are priorities in the years ahead, and they ought to be attained by a simultaneous truncation of the environmental footprint, in other words, an optimisation of resource utilisation as well as adverse environmental impacts. In other words, the focus ought to be on sustainable production (efficiency) and consumption (sufficiency).
\end{abstract}

Keywords: financial pinch analysis, optimisation, pinch analysis, waste management pinch analysis (WAMPA), water pinch pnalysis

\section{Introduction}

As the population of the world increases, the demand for resources of different types will also follow suit. The world needs to accept and adjust to aggravating resource scarcity as an unavoidable challenge in the future. Be it due to climate change or simply due to demand being greater than techno-economically feasible supply, it is imperative to gear up to this challenge. Most of the population increase in the years to come, is likely to happen in the developing world. Half of this is expected to happen in eight developing countries - India, Nigeria, Pakistan, Democratic Republic of the Congo, Ethiopia, Tanzania, Indonesia and Uganda. ${ }^{[1]}$ India, China, Nige-

Received: June 15, 2019 Accepted: June 23, 2019 Published: July 10, 2019

* Correspondence to: G Venkatesh, Department of Chemical and Engineering Sciences, Karlstad University, Karlstad, Sweden; Email: venkatesh.govindarajan@kau.se

Citation:G Venkatesh. Pinch analysis, as a technique for optimising resource utilisation and promoting environmental sustainability: A review of recent case studies from the developing world and transition economies. Resour Environ Inf Eng, 2019, 1(1): 1-17.

Copyright: (c) $2019 \mathrm{G}$ Venkatesh. This is an open access article distributed under the terms of the Creative Commons Attribution License, which permits unrestricted use, distribution, and reproduction in any medium, provided the original author and source are
credited. ria, Pakistan and Indonesia will house more than 300 million people each. Some other African countries will see a quintupling of their populations by 2100 Malawi, Mali, Niger, Zambia and Somalia for instance, in additions to the ones named above. The life expectancy in the developing world is also likely to increase, with the child mortality rate going down appreciably at the same time. Scarcities of different types of resources in different parts of the developing world, will be realities to contend with. Sustaining the anthroposphere in the developing world augmenting social welfare and managing economic development - will not be possible without effective management of our environmental sources (resources) and sinks (spheres into which we discard our wastes).

Pinch analysis, as a technique to optimise the utilisation of resources, traces its beginnings to the 1970s in Switzerland and the UK ETH Zurich and Leeds University to be more precise. It was the oil crisis and the Limits to Growth report, ${ }^{[2]}$ the latter reinforcing belief in the Malthusian prediction (in 1779) of population growth outpacing agricultural production; which may have sown 
the seeds of pinch analysis in the 1970s. It was towards the end of that decade that the first articles on pinch analysis were published Linhoff; ${ }^{[3]}$ Boland \& Linhoff. ${ }^{[4]}$ This was about the same time when many other tools and techniques for optimisation of resource utilisation and environmental management environmental sustainability in other words were nascent. Environmental Life Cycle Analysis was one of them.

Pinch analysis, from its 'source' in heat recovery, Switzerland and the UK, has now entrenched itself in research circles around the world, and also expanded its domain into areas other than energy engineering one reads about water pinch, financial pinch, solid waste management pinch, mass pinch, hydrogen pinch, and even applications in production planning (time as a resource) and human resources management. While Kleme \& Kravanja ${ }^{[5]}$ is a must-read for anyone who wishes to follow the birth and development of pinch analysis from the 1970s till the second decade of the 21st century, Kemp ${ }^{[6]}$ is a very good source of reference for understanding the pinch analysis methodology. While Morgan, ${ }^{[7]}$ a decade and a few years after pinch analysis was 'born', reported that pinch analysis significantly improves both the process design and the design process, Steinmeyer ${ }^{[8]}$ expressed concern that pinch analysis, by narrowing down the focus, may miss out on major opportunities for improvement in other words, it may miss the wood for the trees, to cull a metaphor. Analysis of the limitations, and development of solutions to overcome these limitations, have helped en route. As limitations have been uncovered and overcome over time, the prospects for pinch analysis have become brighter progressively. Tan RR et al. ${ }^{[9]}$ has focused on the future prospects of pinch analysis, highlighted several the strengths and opportunities of this tool in industrial/production management.

The motive behind this article is to perform a focused, selective review of recent publications from the developing world and transition economies, having pinch analysis as their 'core and gist'. The focus has been restricted to papers originating from (and case studies of) the developing world. This is because, as mentioned earlier, most of the population growth in the future will happen in the developing countries, and it is here that social wellbeing and economic development (both of which are related directly to resource consumption) will be strong priorities. But in the interest of sustainable development, these two priorities need to go hand in hand with a simultaneous truncation of the environmental footprint, in other words, an optimisation of resource utilisation as well as adverse environmental impacts. Applications of pinch analysis which have already been done in these countries, will serve as trendsetters for more of them in the future, in all the domains referred to earlier in this sub-section.

It goes without saying that the articles reviewed form just a subset of the vast body of knowledge which forms a strong bedrock now, for research in this niche area of production engineering and resource management. Among other things, this review paper adopts sector-wise, optimised-resource-wise and country-wise perspectives, while throwing light en passant on the main outputs of the papers as well as the complementary methods devised, introduced and applied by the authors. It is not a conventional review paper not just a critique of the methodology per se but a 'historical account' of 'research and development in pinch analysis', of late, which subsequently narrows down its scope to focus on the development. It thus provides insights into the application of 'Pinch Analysis' in the developing world, and based on feedback obtained from colleagues and students at the author's university, will be useful to readers researchers, faculty members and students of pinch analysis alike.

\section{Methodology}

\subsection{Source}

The author has adopted a very simple approach to constructing a list of publications to be read and reviewed for this paper. The source referred to was Scopus. Only 'pinch analysis' was used as the search-phrase, and the time-span was restricted to 2008-2018. Knowing well that pinch analysis has been written about from the 1970s, and reviews of publications from the 20th century already exist in literature, the intention was to narrow down the temporal 'analysis boundary' to the last ten years, in which, as we notice, the extension of the technique to resources other than heat has happened quite conspicuously. The basic premise for selecting Scopus was the well-known fact that Scopus is the largest database in vogue 14000 journal titles from 4000 publishers worldwide - and thereby there is a likelihood of most (if not all) publications related to known fields of research like pinch analysis, being accessible using it. Of course, there may be some journals and thereby publications which may tend to get left out, but this would be a small fraction and perhaps negligible. A claim to comprehensiveness has not been made thereby. The range is certainly limited by the choice of the source and the rationale behind it, the limitations of which, this author is aware of.

\subsection{Search}

Only those publications with 'pinch analysis' in their titles have been read and reviewed in this paper. That of 
course, may at first-thought, seem to be a key limitation, as there obviously are pinch-analysis-based publications where the term may appear in the Abstract and/or the Keywords, but not the Article Title. The intention was to focus only on such papers, the core, crux and gist of which, would be 'pinch analysis'. Anyone who would want a paper to be based primarily on an application of pinch analysis would certainly include that term in the title of the paper. The term 'pinch technology', in the opinion of this author would refer to the implementation, post-analysis. Pinch analysis would be done always as the first step and it may or may not be followed by the actual technological implementation (pinch technology, layout redesigning etc.) From this point of view, almost all publications would essentially be pinch analysis, with or without a pinch technology component. While filtering out further, it was found that some articles related to orthopaedics and plasma physics were also listed- 'pinch analysis' being used in a more literal sense in those papers. These were excluded, and the list whittled down to a little under 160 publications.

\subsection{Trend over time}

Figure 1 and Figure 2 summarise the post-filtering search results.

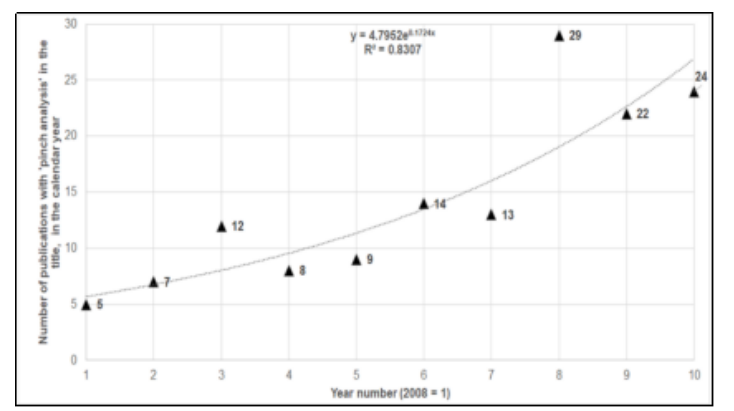

Figure 1. Graphical representation of the spread of the publications over the period 2008-2017 (Year 2018 has been excluded as it is the current year and there would be more publications related to pinch analysis before the end of the same)

If publications in year-2018 the ongoing year - are excluded (in the third month of the year, at the time of writing this paper, there are 10 results), as Figure 1 shows, there is an exponential growth in the number of publications, which may lead one to expect 32 publications in 2018, before the end of the year. While there are 56 journals (refer Appendix A) in the list of 153 publications, Figure 2 shows only those with 5 or more publications over the chosen time period. As seen, the domains encompassed are chemical engineering, environmental engineering, energy and thermal engineering, industrial and production engineering.

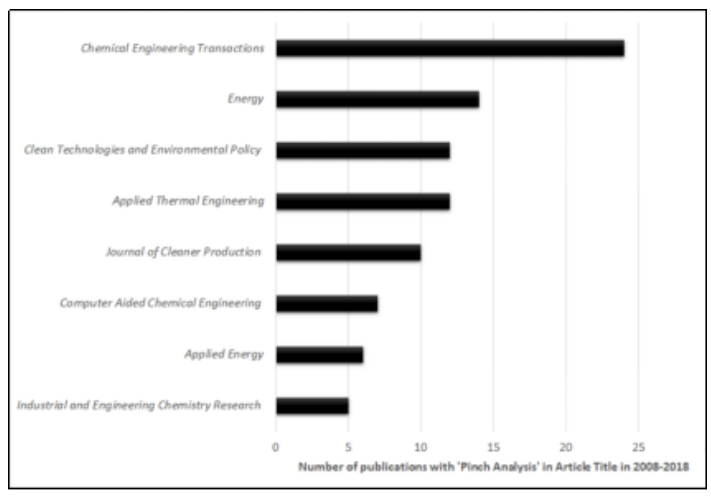

Figure 2. Journals with five or more publications having 'Pinch Analysis' in their titles, over the period 2008-2018

\subsection{Subset from developing world}

The papers filtered out, could be placed in two broad categories those making contributions to methodology and theoretical understanding, and those focusing on applications of pinch analysis. From the second category of papers, a secondary filtering was done to identify case studies from the developing world and transition economies (almost all of these also originated from universities in those countries). The countries represented (Figure 3) include China, Malaysia, India, Iran, The Philippines, Egypt, Thailand, Brazil, South Africa, Colombia, Romania, Bhutan and Sudan (Greece featured alongwith India and Malaysia in comparative analyses).

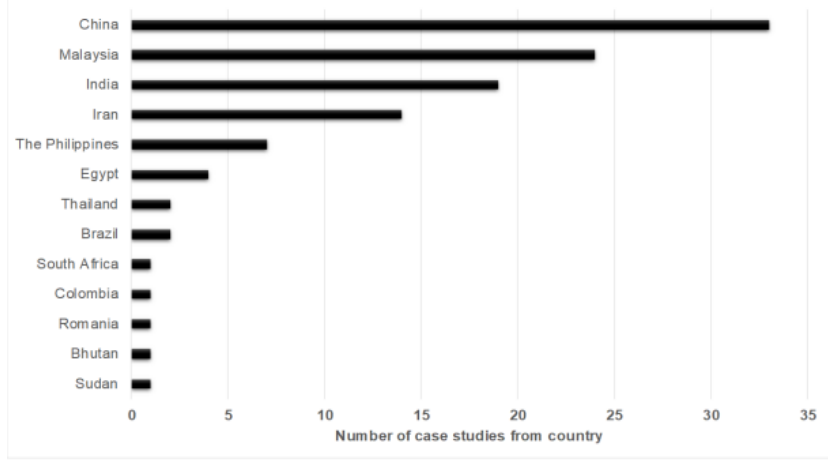

Figure 3. The distribution of the publications based on case studies from the developing world and transition economies

\section{Literature review and analysis}

Figure 4, which is also the graphical abstract for this article, shows the shares of the resources (or environmental emissions) primarily focused on, in all the publications (including the ones from the developed countries). It must be mentioned at this juncture, that quite a few publications have a primary focus on multiple resources with some of them beginning with a carbon 
emissions pinch analysis and extending the results to look at water footprint, land footprint etc. ${ }^{[10]}$ This 'multiplicity of foci' has been incorporated into the pie chart in Figure 4. In many of them, economic benefits associated with the optimisation of resource utilisation (water or energy usually) focused on, and/or greenhouse gas (GHG) emission reductions, follow as a corollary. This further reinforces the usefulness of pinch analysis as an enabling tool for interventions facilitating global, economy-wide sustainable development.

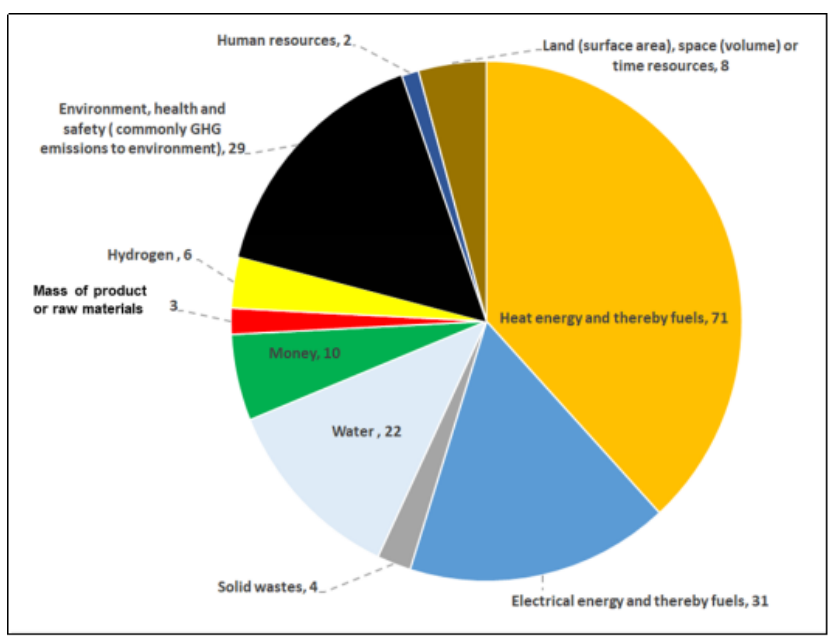

Figure 4. The primary focus (or foci) of all the publications (including the ones from the developed world)

As expected, power pinch analysis dominates with heat energy recovery being the focus in 71 publications, vis--vis the optimisation of utilisation of electrical energy (31). It follows, referring to the legends in Figure 4 , that optimisation of energy directly results in reduction in the consumption of fuels. The focus on carbon dioxide $\left(\mathrm{CO}_{2}\right.$ or GHGs in general) emissions pinch analysis (global warming evidently being a concern which is being addressed by researchers all over the world) is stark from Figure 4, though it must be pointed out that some of the 29 publications focus on workplace risk minimization. Of course, reduction in GHG emissions results from, inter alia, a decrease in the use of heat or electrical energy.

\subsection{Sectoral applications}

The publications have been segmented based on the area/sector in which pinch analysis has been applied in the publications from the developing world / transition economies. Broadly, these are Power and Fuels; Chemical, Pharmaceutical \& Petrochemical; Food; Urban systems, Construction materials, Rubber and Paper; and Industrial sites in general (Refer Appendix B).

\subsubsection{Power and fuels}

\subsubsection{Power generation}

Most of the case studies from the power sector, were published towards the end of the timespan chosen - There are six papers by Rozali et al., ${ }^{[11-16]}$ two by Patole et $a l .,{ }^{[10,17]}$ and a few by Krishna Priya and colleagues Priya et al. (2015B) Priya \& Bandyopadhyay. ${ }^{[11,18-22]}$ Despite declines in coal's generation share in China, thanks to the government's commitment in 2017, of an investment of USD 360 billion in renewable energy, the International Energy Outlook-2017 reports project that coal will continue to be an important component of China's electricity mix, peaking at nearly 4,400 billion $\mathrm{kWh}$ in 2030. By 2040, coal and natural gas would most likely be providing over $55 \%$ of the countrys total electricity. ${ }^{[23]}$ A likely surge in coal consumption in power generation makes India, the largest source of growth in global coal use, in the years to come. Oil demand too will increase by more than in any other country, and reach 10 million barrels per day by $2040 .^{[24]}$ The electricity mix now is dominated by coal, oil and gas (73\%), and despite efforts being made to increase the share of renewables to $40 \%$ by year- 2030 , the power sector will continue to be a major global source of greenhouse gas (GHG) emissions. It is in this backdrop that the application of carbon emission pinch analysis (CEPA) as a tool to advise the electricity sectors in India and China by Priya \& Bandyopadhyay ${ }^{[19]}$ and Li Z et al. ${ }^{[25]}$ respectively, is noteworthy. These researchers tested the impact of improving the share of renewable energy in the mix, on the truncation of the country's carbon footprint as economically as possible.

By using pinch analysis and exergy analysis in tandem, (which Ataei \& Yoo ${ }^{[26]}$ label as Combined Pinch and Exergy Analysis or CPEA), Farhad et al., ${ }^{[27]}$ in a case study of four Iranian thermal power plants, could show that better heat integration could easily enable the reduction of the consumption of fossil fuels by 64,000 tons. Of course, it goes without saying that this would play a significant role in the truncation of Iran's carbon footprint. It must be mentioned at this point, that CPEA will be a very useful tool for Iranian researchers helping the government to tackle climate change which is having an adverse impact on the country's water resources and forests. Also noteworthy is the fact that the power sector accounts for $90 \%$ of these emissions. The other publications which have originated from Iran have also been evidently been motivated by this top-down approach whereby policy-making (a reduction target set by the government, in this case) motivates researchers to contribute to the decision-making process. In addition to reducing GHG emissions, if carbon capture and stor- 
age systems (CCS) are also set up to further truncate the carbon footprint (as in $\mathrm{CO}_{2}$ emitted to the atmosphere) of power plants, more ambitious reduction targets can be set and attained in the developing world. Many researchers from India, Malaysia, the Philippines, Iran and China have, by availing of CEPA as a tool, shown how the installation of CCS systems can be optimised, while making sure that the power output and thermal efficiency of the power plants alongside them are not adversely impacted. The author would like to refer to Tan RR et al. ${ }^{[28]}$ Harkin et al., Wang Z et al., ${ }^{[29]}$ Ooi et al. ${ }^{[30]}$ Zhang K et al.,${ }^{[31]}$ Priya \& Bandyopadhyay (2015A) and Valiani et al. ${ }^{[32]}$ in this context.

Integrated Gasification Combined Cycle (IGCC) Plants are common in Iran's power sector; and as such they have a higher efficiency than steam turbines and gas turbines operating separately. However, there is a possibility of further improving the efficiency, thanks to insights obtained from pinch analysis. The CPEA used by Farhad et al. in $2008,{ }^{[27]}$ to demonstrate the possibility of a reduction in resource usage and environmental impacts, and an improvement in energetic efficiency, was applied ten years later by Asl et al. ${ }^{[33]}$ and Khoshgoftar Manesh \& Rosen, ${ }^{[34]}$ in combination with an economic analysis, on an Iranian IGCC plant. This is one of the many publications which at once demonstrates the applicability of companion tools to analyse resource optimisation possibilities in the industry.

Pinch analysis, in the instances above, in concert with exergy and economic analyses, is useful when interventions to reduce environmental impacts are planned. While GHGs may be the focus of many countries India, China, Iran etc. energy saving can also easily be correlated with a reduction in other emissions and thereby a host of environmental impact categories, as Gadalla et $a l .{ }^{[35]}$ have shown by correlating energy saving (courtesy energy recovery using heat exchangers) in power plants to reduction in emissions of $\mathrm{CO}_{2}$, nitrogen oxides (NOx) and sulphur dioxide. NOx emissions are responsible for photochemical oxidant creation and/or eutrophication and/or acidification, while sulphur dioxide is a well-known cause of acidification of water bodies and agricultural/forest soils.

The possible improvements uncovered may at times seem insignificant, but when viewed from the perspective of the entire operation phase of a power plant, small daily savings in resource usage translate into substantial gains in the longer run. Take for instance, the Mexican study conducted by Arriola-Medellin et al., ${ }^{[36]}$ in a thermal power plant. CPEA came in handy for ArriolaMedellin et al. ${ }^{[36]}$ who proved that during process redesign, if cross-pinch heat transfer could be avoided in a Mexican thermal power plant, its efficiency could be increased slightly - by 0.81 percentage points and the cooling water consumption could be reduced by $2.4 \%$. These may seem to be small and insignificant, but in the interest of the environment and resource conservation, it is worth the effort. Moreover, if water scarcity is going to be an imminent challenge in the future, any reduction in water demand is most welcome, anywhere in the world, in any sector. Mexico, it must be pointed has a fossilfuel-heavy power sector (over 70\%, like India's), and the expected growth in population is bound to stress water resources in the country in the years to come.

Malaysia is not just a major producer of oil and natural gas, but it uses a good portion of the domestically extracted fossil fuels (coal included) in its own power sector, and this may probably be the case in a business-asusual scenario. Truncating the country's carbon footprint is certainly a point on the government's agenda. Working from Malaysia, Wan Alwi et al. ${ }^{[37]}$ introduced a new tool based on pinch analysis, which they labelled as the outsourced and storage electricity curves, to support powerplant planning. While elaborately discussing the merits of a hybrid power system (HPS), they showed how one could design an HPS to reduce the electricity load on the grid, as well as the required storage capacity. The option of optimising storage capacity (reduction by $50 \%$ as shown by the authors), will perhaps promote investments in solar-PV and wind power, if the merits hereof are communicated clearly to decision-makers in the country. Lee MY et al.,$^{[38]}$ building on studies like Wan Alwi et al. ${ }^{[37]}$ emphasized on the expediency of better powerplant planning in the 21st century in Malaysia (and globally, for that matter), and determined using Electric System Cascade Analysis (ESCA) that a total power plant capacity of $0.929 \mathrm{GW}$ and energy capacity of the storage systems equivalent to $2.6 \mathrm{GWh}$ would be required for the country. ESCA is an optimisation technique for the design and scheduling of a distributed energy generation system based on pinch analysis, with the objective of ensuring maximal thermal efficiency of the powerplant. What Wan Alwi ${ }^{[37]}$ tested for Malaysia in 2013, Rozali et al. ${ }^{[1-16]}$ did for Iran, in the next four years, in a clutch of publications focusing on various aspects of the HPS and load reduction on the grid. Among other things, they tested the possibility of diesel stand-alone generators being considered as add-ons to the grid, and studied the effect of the feed-in tariff on integration of different sources of power generation to the grid. This economic aspect which was the focus of Rozali et al. ${ }^{[15]}$ extends the other analyses carried out by them earlier, into the realm of practical possibilities and hurdles, related to governance and policy-making. Bandopadhyay 
et al. ${ }^{[39]}$ and Liu, WH et al.,${ }^{[40]}$ applied the ESCA which Lee, MY et al. ${ }^{[38]}$ had introduced a year earlier, in their Indian and Malaysian case studies respectively.

In what could be looked upon as a contribution to pinch technology, Guo et al. ${ }^{[41]}$ and Wu S et al. ${ }^{[42]}$ focused on the design of heat exchangers (subsequent to performing pinch analysis and determining the potential for energy saving) in thermal power plants adopting the organic Rankine cycle (common in engineering parlance as ORC), and stressed on the importance of locating the heat transfer pinch point correctly to factor in the reduction of resistance loss. The process design in an ORC plant is guided by a combination of factors process fluid selection, thermal efficiency, economics and the sizes of the components. Higher efficiency, lower life-cycle costs and optimised component sizes would be the targets an engineer would set for himself. Sarkar ${ }^{[43]}$ performed a comparative analysis of three different fluids ammonia, R152a and toluene and concluded that depending upon the priorities set, ammonia is preferable in terms of higher thermal efficiency and lower component size; $\mathrm{R} 152 \mathrm{a}$, if a higher net power output is the main requirement; and toluene, if the goal is to optimise the life-cycle cost.

Offshoots of pinch analysis have mushroomed during the timespan considered in this review, and many of them have either originated in and/or been applied in the developed world. Like ESCA, CEPA and CPEA, there is the so-called SAHPPA or stand-alone hybrid power pinch analysis, which has been applied by Ho et al. ${ }^{[44]}$ in Malaysia, and Norbu \& Bandyopadhyay ${ }^{[45]}$ in Bhutan the latter co-authoring with Bandopadhyay, to study the optimisation of standalone, off-grid (decentralized, in other words) renewable HPS with nonintermittent biomass/biofuel and intermittent wind and solar energy as the sources. This is of particular relevance to electrification of remote areas in the developing world, which is one of the many challenges/priorities of many developing world governments. As far as alternate energy sources (renewable preferably) being sought by the energy sector in many parts of the world are concerned, hydrogen gas is being touted as a prominent one in the future, with fuel cells likely to be better-entrenched globally. From a futuristic perspective, the study of Ghosh et al. ${ }^{[46]}$ which has applied pinch analysis to optimise the size of the reformer of the fuel cell and the storage volume of the buffer tank, in what they call the 'design space' of the system, deserves mention.

Sustainability thinking entails holism; and advises against 'cross-subsidizing'. In other words, too much focus on reducing the consumption of one resource may result in the increase in the consumption of some other resources. Too much focus on reducing one type of environmental impact may result in 'problem-shifting' or an undesirable increase in some other types of impacts. This is where multi-objective pinch analysis (or multidimensional pinch analysis) holds promise for the future. Three papers by Priya et al. ${ }^{[20]}$ Priya \& Bandyopadhyay ${ }^{[20,21]}$ have shown how this can be done for power plants. Of course, one may start off by focusing on a single resource, but the need for a more holistic outlook at once becomes clear. Power plants use water, fuels of diverse types and emit GHGs. There is also the need to match demand to supply and invest in storage technologies as many other papers referred to earlier have discussed. The analysis is also incomplete without giving a thought to land use and economics. Certainly, the relative importance of the different objectives is not the same in different parts of the world, at different times. Patole et al. ${ }^{[16,17]}$ have added to the body of knowledge related to multi-objective pinch analysis by developing what they term as a composite quality index, which factors in carbon footprint, water footprint, land footprint, 'emergy transformity', energy return on investment, human fatalities and inoperability risk, each of which is assigned a weightage using the well-known Analytic Hierarchy Process. In the same year as Patole et al. ${ }^{[16]}$ was published, Jia X et al. ${ }^{[47]}$ applied multi-dimensional pinch analysis to the electricity sector in China, factoring in some of the aforesaid footprints/indices. Jia $X,{ }^{[47]}$ as we shall also see later, has played a key role in expanding the application of pinch analysis to different types of resources in different industrial sectors.

\subsubsection{Oil and gas}

Zhang Q et al. ${ }^{[48]}$ and Huang FL et al. ${ }^{[49]}$ showed that the pinch analysis technique could be applied to minimise the demand for fresh hydrogen in the petroleum industry. Four years after studying the potential for reduction in the use of hydrogen, Zhang Q et al. ${ }^{[50]}$ considered a type of multi-criteria pinch analysis, with the reduction of consumption of both water and hydrogen being considered. If demand for fresh hydrogen can be minimised in the petroleum industry, what is saved can find use in fuel cells in the future, when that technology entrenches itself in China. With electric vehicles slowly entering the private transportation sector in the country, it is necessary to make sure that the demand for thermal power does not increase. Fuel cells can be placed upstream to power the charging stations on highways, for EVs. ${ }^{[51]}$

The water problems in Iran have loomed over time, necessitating immediate mitigation actions ${ }^{[52]}$ Though over $90 \%$ of the water consumption is in agriculture and that 
sector needs to be considered as the hotspot to be rectified, small efforts made in the oil and gas sector will also certainly contribute. Water was the resource focussed upon in three Iranian publications - Bidhendi Nabi et $a l .{ }^{[53]}$ and Mohammadnejad et al. ${ }^{[54,55]}$ in a case study of an oil refinery in Tehran. Water scarcity, this goes to show, has been a relatively chronic challenge the Iranians have been facing. The freshwater use reduction (by way of water cascading within the refinery) achieved with double-contaminant and triple-contaminant water pinch analysis was $40 \%$ and $17.4 \%$ respectively. In Mohammadnejad et al., ${ }^{[55]}$ the authors also considered each parameter hardness, COD and suspended solids separately, and arrived at $60 \%, 43 \%$ and $17 \%$ reduction in freshwater use respectively.

The refrigeration cycle of a natural-gas-liquids recovery unit in Iran was optimised by Ghorbani et al. ${ }^{[56]}$ by using CPEA, and the changes implemented on the basis of the advice these tools provided (the pinch technology subsequent to pinch analysis), resulted in a reduction of the compressor work by $570 \mathrm{~kW}$ and a drop in refrigerant demand by $11.5 \%$. Energy saving apart, a truncation in the environmental impacts associated with refrigerant production and transport to site is also achieved. When calculated for the entire operation phase of the lifetime of the plant, the economic and environmental benefits are not insignificant. In a similar paper, Thasai \& Siemanond $^{[56]}$ in a Thai case study of a liquefied natural gas plant, justifies the application of CPEA by rightly observing that pinch analysis cannot account for shaft work and therefore, exergy analysis is also needed in order to improve energy efficiency in a holistic manner (both heat and work and thereby electricity, in other words). The olefin production process in an oil refinery was the subject of interest for Ataei and Beninca et al. ${ }^{[58]}$ in two separate studies carried out in Iran and Brazil respectively. While the former used the same methodology as Thasai $\&$ Siemanond ${ }^{[57]}$ and Ghorbani et al. ${ }^{[56]}$ and concluded that a total energy use (shaft work plus energy) reduction of close to $2.5 \mathrm{MW}$ could be achieved which when accounts for the number of hours in a year the plant operates in a year, translates into significant savings - the latter tested various mathematical optimisation techniques and contributed to the methodological development of CPEA.

Process redesign on the basis of the outputs of pinch analysis can be expensive. But if the focus is not just on the capital cost, but on the net benefits over the entire lifetime of the plant, economic feasibility is at once detected and the pinch analysis can give way to the pinch technology implementation. In a study of catalytic cracking of a refinery fluid, a capital investment of about 1 million USD, for a design $\mathrm{T}$ min of $26{ }^{\circ} \mathrm{C}$, reduced the hot and cold utility demands significantly and further benefits were availed of by integrating two heat exchanger networks in the refinery ${ }^{[59]}$ Cui \& Sun ${ }^{[60]}$ also demonstrated the benefits of inter-unit coupling in a crude oil distillation plant in China, and showed that economic benefits could be easily increased. These, one can say, are examples of navigating the realm between process integration and total site integration. Heat exchanger network synthesis using mixed integer nonlinear programming (MINLP), subsequent to pinch analysis using hot and cold stream data from a gas separation unit in Thailand design, by Angsutorn et al., ${ }^{[61]}$ shows how the number and sizes of heat exchangers can be optimised, in order to improve the economic feasibility of energy recovery installations.

CCS was one of the themes in the pinch analysis publications focusing on the power sector. While the thermal sector is one source of $\mathrm{CO}_{2}$ emissions, the petroleum sector is another. CCS, in general involves multiple sources of emissions and multiple sinks or storage sites in a many-to-many relationship. The sinks include geological formations such as depleted oil or gas wells, inaccessible coal seams, and saline aquifers. Using CEPA, researchers from the Philippines, Malaysia and India, have shown how the sources in the case of that paper, petroleum refineries and thermal power plants - can be matched to the sinks for a given region/country. ${ }^{[62]}$ This is a useful offshoot / addendum to the CEPA methodology, which can be applied for selected cases regions or countries.

\subsubsection{Biofuels - bioethanol and biodiesel}

Biofuels replace fossil fuels in a country's energy mix and the $\mathrm{CO}_{2}$ emissions resulting from their combustion are considered to be biogenic and thereby not contributing to global warming. However, fossil energy may be needed upstream in the conversion of feedstock to biofuels. In order to maximise the environmental benefits of replacement of fossil fuels with biofuels, the upstream energy use has to be controlled.

In a case study conducted in the Philippines, with sugarcane and corn considered as the possible sources of bioethanol production, Tan RR, et al., ${ }^{[63]}$ studied the limitations imposed by freshwater resources in three selected regions in the archipelago for sugarcane/corn cultivation, on satisfying internal demand for bioethanol. While the focus was on water as a resource in this paper and the tool goes by the name 'water footprint pinch analysis', the authors recommended a multiple criteria pinch analysis, with land use and GHG emissions as the two additional criteria. Land use is a critical factor in 
the Philippines which has a population density of over 350 inhabitants per square kilometre. The power sector in the country is also heavily reliant on the coal, oil and natural gas (over 72\%), and this necessitates all possible measures across the national economy, to reduce GHG emissions.

Brazil has been in the forefront in the biofuels sector for quite some time now and in a Brazilian case study conducted by Palacios-Bereche et al., ${ }^{[64]}$ the authors have concluded that adopting mechanical vapour compression in bioethanol production from sugarcane, reduced steam consumption by $10 \%$ in the evaporation system of the plant. They have also recommended thermal integration of the vapour compression process to other streams in the process chain to further improve the energy efficiency. Petersen et al. ${ }^{[65]}$ in a South African study, rated gasification and Fischer Tropsch synthesis of ethanol from sugarcane bagasse over hydrolysis-fermentation and simultaneous saccharification-fermentation, with respect to energy efficiency, after exploring thermal integration possibilities using pinch analysis.

The food-fibre-fuel debate and the resulting competition for and stress on water and land resources, resulted in microalgae emerging as a kind of a 'silver bullet' solution some years ago. Algal biodiesel is gradually foraying into the scene and in a few years, it would have realised its full potential, thanks to concerted research being undertaken in universities around the world. In a Colombian study, Sanchez et al. ${ }^{[66]}$ investigated the possibility of improving the energy efficiency of producing biodiesel from microalgal oil, through esterification and transesterification and using pinch analysis deduced that by resorting to heat transfer between cold and hot streams, reduction of cooling and heating duty respectively by $11.3 \%$ and $13.3 \%$ could be achieved. In addition to optimising energy use, a water pinch analysis also revealed that water in the biodiesel from esterification could be flashed out and then reused in further stages of washing. Though the authors did not perform an economic feasibility analysis in this paper; they have recommended the same as it is necessary to find out whether the heat exchangers would fetch the plant an attractive Return on Investment. CPEA figures in Jia $\mathrm{Z}$ et al., ${ }^{[67]}$ in which barley straw replaces microalgae as the source for biodiesel. The pinch analysis results pointed to a reduction in the process exergy loss by $23 \%$. Among the pinch technology implementation measures recommended by the authors, in addition to the installation of heat exchangers, are an increase in the reaction temperature and an adjustment in the ratio of reactants.

\subsubsection{Chemical, pharmaceutical and petrochemical}

Yang JK et al. ${ }^{[68]}$ have focused on some very practical considerations that must not be forgotten when pinch analysis is applied in chemical and petrochemical industries. Proper selection of sub-systems (sets of energyusing / energy-transporting processes in other words) within larger systems is extremely important if the plant wishes to recover energy without incurring high expenditures for the retrofitting that may be needed. In a review paper on water pinch analysis (or water network synthesis as it is alternately called), originating in Malaysia, Foo et al ${ }^{[69]}$ have discussed the development in this particular application of pinch analysis in the chemical sector over the years starting from the 1990s, and well into the 21st century.

Wang et al. ${ }^{[70]}$ in a paper in which they have developed the approach tested by Tan $R^{[71]}$ further (Tan RR also happens to be a co-author in the former), have used segmented pinch analysis to advise environmental risk management measures in the chemical industry. They have devised a method based on the 'willingness to pay' standards, which has the risk management costs on the Y-axis (for the sink curve) and the degree of criticality of the risk on the $\mathrm{X}$-axis (for the source curve). The top right-hand point of the sink curve (or the sink line) is determined by the constraints on funding which the industry has to be operate within. Here, mention must also be made of Tan RR et al. ${ }^{[9]}$ which preceded Tan RR et $a l .{ }^{[25]}$ and Wang et al., ${ }^{[70]}$ and was one of the steppingstones in the development of the pinch analysis method for providing advice to environmental risk and industrial safety management. Methanol, a key product from the chemical sector, can be produced from either coal or biomass. Of course, the former approach will confer a large carbon footprint to this alcohol-product. Qin et al. ${ }^{[72]}$ using CEPA, have advised expediency with regard to the replacement of coal with biomass as a source for methanol production in China, and as it would invariably take time, they have recommended the retrofitting of at least $65 \%$ of the currently-operating coal-to-methanol plants with carbon capture and storage facilities. Coalto-methane was also the focus of Jia X et al. ${ }^{[73]}$ but water was the resource under consideration, and water pinch analysis revealed that a reduction in freshwater use of $16 \%$ could be achieved with effective internal water cascading. CEPA was also used in an earlier Chinese case study by Jia XP, et al. ${ }^{[74]}$ to show that vis--vis the thenexisting energy planning for a chemical industry park, a further reduction of $10 \%$ in GHG emissions could be achieved. In yet another paper dealing with $\mathrm{CO}_{2}$ emissions control in the Chinese chemical industry, Yu YS et $a l .{ }^{[75]}$ determined the so-called synergy pinch point with 
zero $\mathrm{CO}_{2}$ surplus and zero energy surplus, and recommended the introduction of an energy-efficient gas stripper with fins.

There are three papers which have focused on three different products and thereby production processes in the chemical/petrochemical sector ethylene oxide, chlorine-caustic soda and triethylene glycol. The first two which have used CPEA are from Iran, while the third which has used only pinch analysis is from China. ${ }^{[76]}$ While the conventional pinch analysis method showed that the cold utility requirement for ethylene oxide production could be minimized to $601 \mathrm{MW}$, using CPEA enabled the authors to uncover a further reduction of 24 MW, in Ghannadzadeh \& Sadeqzadeh. ${ }^{[77]}$ As noted earlier, Thasai \& Siemanond ${ }^{[57]}$ had observed that while pinch analysis focuses on heating and cooling, exergy analysis factors in work as well. In the case of Ghannadzadeh \& Sadeqzadeh ${ }^{[78]}$ which adopts the same approach as the former to study the hot and cold streams of a chlorine-caustic soda production process, CPEA suggested a possibility of raising the hot utility requirement slightly by $430 \mathrm{~kW}$ (from $7.74 \mathrm{MW}$ to $8.17 \mathrm{MW}$ ), while reducing the cold utility demand considerably by $97 \%$ (from $13 \mathrm{MW}$ to $400 \mathrm{~kW}$ ), resulting in a net reduction in energy use.

In a petrochemical industry case study from India, $\mathrm{Rao}^{[79]}$ showed that the investments in heat exchangers made in energy recovery in an acrylic acid production plant could be recovered in just under 4 months, Ma et $a l .{ }^{[80]}$ studied a butanone-toluene dewaxing process and showed using pinch analysis that retrofitting investments of 1.82 million RMB (Chinese Renminby) could reduce hot utility and cold utility requirements by $30 \%$ and $32 \%$ respectively, and save over twice of what is invested, annually (in other words, a payback period of less than 6 months). These are just two of the many pinch analysis studies which go to show that oftentimes, simple solutions which do not cost a lot, yield impressive benefits, if one can think laterally and initiate changes.

\subsubsection{Food sector}

Balla et al ${ }^{[81]}$ by conducting a water pinch analysis for a sugar factory in Sudan showed that the freshwater extraction could actually theoretically that is be reduced to zero, if the vapour condensate which results when the water inherent in the sugarcane is separated from it and then cooled, can be completely recovered and used in the sugar production processes within the factory. Sugar production is a water-intensive process, which of course can also benefit from energy use optimisation, which may, at the time of writing, not be a priority in oil-rich Sudan. It goes without saying that an arid country like Sudan however has to avail of all measures to reduce the water footprint of industrial processes. Results from Balla $e t$ $a l .{ }^{[81]}$ the first Sudanese case study of its ilk, hopefully will set a trend in that water-scarce country.

\subsubsection{Urban systems \\ 3.1.4.1 Water and wastewater systems}

If climate change leads to depletion of freshwater resources, even as the population keeps increasing, humankind may need to turn to saltwater and brackish water to bridge the demand-supply gap. Even if solar energy is used for desalination, there is always a possibility of recovering a substantial amount of that energy and putting it to good use for some other process. Hou et $a l .{ }^{[82]}$ used thermal pinch analysis to test the possibility of energy recovery in a solar desalination humidificationdehumidification system and showed that a two-stage system can accomplish $83.6 \%$ thermal energy recovery when the temperature difference at the pinch point can be brought down to $1 \mathrm{oC}$ and that increasing the number of stages makes the recovery converge to $90 \%$. Of course, increasing the number of stages will entail additional investments, but the marginal benefits may not justify them. This is where a cost-benefit analysis needs to be performed in order to maximise the net benefits. Esfahani \& $\mathrm{Yoo}^{[83]}$ used water pinch analysis as a tool to determine that a solar-powered reverse osmosis (RO) desalination system which will be able to cater to the total demand for treated water in Kish Island (Iran), will entail the installation of 92 photovoltaic panels, 11 reverse osmosis $(\mathrm{RO})$ membranes and a desalinated water storage tank with a capacity of $63 \mathrm{~m}^{3}$. In a study similar to Hou et al., ${ }^{[82]}$ Kang et al. ${ }^{[84]}$ compared the energy recovery potentials of two types of multi-stage desalination system (regenerative and air-extraction) using thermal pinch analysis, varying the pinch-point temperature differential the so-called Tmin and the number of stages, and concluded that the recovery rate in the former case was better. In contrast to Hou et al. ${ }^{\left[{ }^{[82]}\right.} \mathrm{Kang}$ et al. ${ }^{[84]}$ also concluded that as the number of stages increases further, beyond two, not only is the enhancement effect weakened, but the performance also deteriorates conspicuously.

Pinch analysis in combination with mathematical programming enabled Li Y et al. ${ }^{[85]}$ to optimise wastewater treatment networks the mixing, treatment and discharge of wastewater streams, and Liang et al. ${ }^{[86]}$ to show that freshwater use reduction is easily attainable in a plant with several water-consuming processes, each requiring water of a different quality (with respect to concentrations of specified pollutants). Kim M et al. ${ }^{[87]}$ by using CEPA (which they refer to, more accurately, as GHG emission pinch analysis), tested three GHG emission reduction strategies in wastewater treatment plants 
increased aeration capacity to increase biogenic $\mathrm{CO}_{2}$ emissions and reduce anaerobically-generated methane emissions, controlled use of external carbon source (petroleum-based ethanol, methanol etc.) in the denitrification step and generation, capture and use of biogas from anaerobic sludge digestion in lieu of fossil-fuels, and determined that the maximum GHG emission reduction could be achieved by adopting the third alternative.

\subsubsection{Transportation}

Malaysian researchers, for reasons not known to this reviewer, seem to be in the vanguard in the application of pinch analysis to resource optimisation in different sectors of the economy. Ramli et al. ${ }^{[88]}$ by applying CEPA to analyse the transportation sector in Iskandar Malaysia, have estimated the minimum amount of electricity that would need to be generated in addition (on the margin, in other words), to have electric vehicles as a part of the road transport fleet, to meet the emission targets unveiled by the government for 2025 , as $0.25 \mathrm{TJ}$.

\subsubsection{Solid waste management}

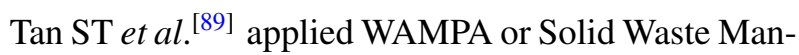
agement Pinch Analysis for Malaysia, with the total cost of handling being fixed as a constraint (the 'source' curve in other words, of funds to be allocated) and the various ways of handling solid waste being represented as the 'sink' curve. The unit costs for the different waste handling methods must be known for this analysis. While Tan ST et al. ${ }^{[89]}$ considered the solid waste management budget as a constraint for Malaysia, the GHG emission target set by the government in Qingdao city, China, forms the constraint in the WAMPA applied in Jia X et $a l .{ }^{[90]}$ The quantities of different types of solid wastes (food waste, metals, glass, paper etc.) to be allocated to different waste handling methods incineration, landfilling, recycling, composting etc., are plotted on what is analogous to the 'sink' or the cold composite curve in thermal energy pinch analysis. This needs to be followed up by an economic analysis to optimise the expenses, and the practical obstacles like capacity constraints must be factored in. Othman et al..$^{[91]}$ had applied a more 'specialised' WAMPA to test the sustainability of landfilling solid wastes in a Malaysian case study. In this paper, the variable on the $\mathrm{X}$-axis, is the landfill area needed.

Ho et al. ${ }^{[92]}$ in a Malaysian case study focusing on sustainable planning for solid waste management (considering a spectra of methods hierarchically from the most desirable to the least; reduce, reuse, recycle, energy recovery and landfilling) applied to a two-decade time-period 2015 to 2035 calculated the possible GHG emissions reduction to be $13.5 \%$ and that of the quan- tities of landfilled wastes to be 55\%. This is achieved, inter alia, by reducing or avoiding the landfilling of food wastes (cause of methane emissions) and the reduction of incineration of plastics for energy recovery. Of course, in a truly sustainable waste management strategy, the possibility of enhancing the scope of reducing waste generation and reusing materials and products ought to be always investigated.

\subsubsection{Construction materials, rubber and paper}

There are different types of energy-consuming processes within a paper and pulp mill. Take coating for instance. Li YG et al. ${ }^{[93]}$ by zeroing in onto the drying section of the coating process unit in a paper and pulp mill, showed by using pinch analysis to explore energy recovery possibilities, that the energy-saving potential could be more than doubled from the $4.82 \mathrm{MW}$ that was extant at the time of conducting the analysis to almost 10 MW, reducing the need for fresh steam in the process. Economic feasibility or the attractiveness of the investment made is always a factor which needs to be considered when decisions regarding introduction of energyrecovering/transferring heat exchangers and reorganising the energy-using and energy-transporting equipment on the shop-floor are to be made. Jabbari et al. ${ }^{\left[{ }^{[9]}\right.}{ }^{\text {working }}$ on a paper-and-pulp mill case study in Iran, studied using pinch analysis to determine where a combined cooling, heating and power plant could be placed in the circuit, in order to optimise the life-cycle costs of installing and maintaining the additional equipment, by maximising the savings which would accrue by way of reducing the expenses incurred on the purchase of energy from external sources. The simple payback period of 3.2 years which they arrived at, is definitely attractive enough and justifies an investment in energy recovery. In what may be labelled as a focused niche review paper, Bakhtiari et al. ${ }^{[95]}$ have discussed how pinch technology has been applied in several paper and pulp mills for optimising energy and water usage and cutting back on wastewater generation.

Roychaudhari et al. ${ }^{[96]}$ have selected the cement and the paper \& pulp sectors as test beds for the application of Financial Pinch Analysis, in which the Fund Composite Curve and the Project Composite Curve are analogous to the Hot Composite and the Cold Composite Curves respectively, in thermal energy pinch analysis. The funds, intuitively, are the 'sources' which 'empty' themselves into projects which are the 'sinks'. This method, the authors have shown, enables one to select a clutch of independent projects from a vast pool of available ones, with the funding being the guiding constraint. In a related paper which followed the previous one, Roychaudhari \& Bandopadhyay, ${ }^{[97]}$ focusing on the Indian paper 
and pulp sector, have demonstrated the usefulness of financial pinch analysis when decision-makers in industry wish to select the best mix of projects by optimally allocating the available funding among them. They have introduced what they call an 'opportunity cost-targeting algorithm', for projects aimed at energy conservation and environmental upkeep.

\subsubsection{Industrial sites in general}

CEPA can be applied to process plants, industrial estates, cities, regions, countries and continents. It determines the best possible way to allocate reductions in $\mathrm{CO}_{2}$ emissions among the different socio-economic sectors (the sources of the emissions), once the government of a region/city/country for instance, has set a target for itself. An economic analysis can be subsequently performed in order to find out the costs of mitigation incurred by the sectors of the economy. While Tan et $a l .{ }^{[98]}$ have used statistical data from the Philippines to test the CEPA methodology for the entire national economy, Abdul Aziz et al..$^{[99]}$ and Mohd Nawi et al..$^{[100,101]}$ demonstrated the effectiveness of this offshoot of pinch analysis for industrial sites in Malaysia by showing that heat integration and the incorporation of renewable energy sources could reduce site-wide carbon emissions by almost 100

Li BH \& Chang, ${ }^{[102]}$ Sun WT \& Hu, ${ }^{[102]}$ Sun L et al. ${ }^{[104]}$ Dimian et al. ${ }^{[105]}$ and Bandopadhyay (2015), though not applications per se, can be looked upon as educational publications which students of pinch analysis can benefit from, when they start understanding and appreciating the usefulness of the technique, while Tewari et al ${ }^{[106]}$ provides guidelines on the use of MATLAB for the application of pinch analysis in case studies. Inter alia, some of the aforesaid papers explain the role played by the least temperature difference between the hot and cold composite curves known in pinch analysis as $\mathrm{T}_{\min }$ in the design of and investment in heat exchangers. Talking of heat exchanger network design, Luo X et al. ${ }^{[107]}$ recommended an integration of pinch analysis and bypass optimal heat exchanger network control, in order to take into account the fluctuations in the operating pinch point temperature and Tmin, which are invariably experienced, in reality.

As has been discussed by some researchers in publications referred to earlier, storage of recovered energy is an important consideration if one needs to avail of most of the benefits which the implementation of pinch analysis confers. Minimizing storage requirements would obviously result in a reduction in the capital investments called for, as discussed by Chaturvedi \& Bandyopadhyay ${ }^{[108]}$ and Brunner et al. ${ }^{[109]}$ Gadalla, ${ }^{[110,111]}$ in three related publications, introduced a novel graph- ical technique which can be looked upon as an offshoot/aid/appendage of the conventional pinch analysis technique. This new approach which the author recommends as a user-friendly educational tool, represents the hot and cold streams as horizontal and vertical lines in a $\mathrm{T}-\mathrm{T}$ diagram (which is different from the $\mathrm{T}-\mathrm{H}$ diagram in conventional pinch analysis).

Quite like optimisation of energy, water and material resource needs, and reduction of GHG footprints, all industrial sites benefit from scheduling work effectively to utilise their human resources optimally. Pinch analysis proves to be a useful technique in this respect. ${ }^{[112]}$ In a paper which advises small and medium-scale industries with insufficient funds and limited resources (capital machinery and human, raw materials, access to water and energy), Lim J et al. ${ }^{[113]}$ have applied pinch analysis to production planning in other words to a good allocation of different resources to optimise productivity and profitability.

\subsection{Geographical origin}

China tops the list with 33 publications, followed by 22 from Malaysia, 17 from India and 13 from Iran. These four Asian countries account for close to $60 \%$ of all the publications reviewed (including the case studies from the developed world which were filtered out). Egypt tops the African list with three. The developing countries (or transition economies) with a single publication against their names include Bhutan, Colombia, Mexico, Romania, South Africa and Sudan. Brazil figures twice, while the Philippines is home to 7 of the publications reviewed. Refer Appendix B, for a listing of these publications, classified sector-wise first and country-wise within the sectors.

\section{Discussions}

This section is a brief SWOT analysis of the pinch analysis technique, based on observations of researchers in the publications reviewed.

\subsection{Strengths}

In the early 1990s, Morgan ${ }^{[7]}$ had stated that pinch analysis had the potential to 'significantly improve both the process design and the design process'. As Figure 4 depicts, from its 'genesis' in the petrochemical sector and focus on thermal energy saving, pinch analysis has diversified into several sectors of the economy and is now being applied to optimise the use of a host of resources. As Table 1 in the next section shows, offshoots and extensions have entrenched themselves over a relatively short period of time. 
Table 1. Offshoots and extensions of pinch analysis and examples of publications introducing or applying them in case studies from the developing world

\begin{tabular}{|c|c|}
\hline Offshoots/complements/extensions & Examples of publications \\
\hline $\begin{array}{l}\text { Carbon emissions pinch analysis } \\
\text { (CEPA) (or) Greenhouse gas } \\
\text { emissions pinch analysis (GGEPA) }\end{array}$ & Qin, et al. [72], Tan RR, et al. [98] \\
\hline $\begin{array}{l}\text { Combined pinch and exergy analysis } \\
\text { (CPEA) }\end{array}$ & Farhad, et al. [26], Ataei \& Yoo [27] \\
\hline CPEA + Economic analysis & Asl, et al.[33] \\
\hline $\begin{array}{l}\text { Electric systems cascade analysis } \\
\text { (ESCA) }\end{array}$ & Lee MY, et al.[38] \\
\hline Financial pinch analysis & Roychaudhari et al. [96] \\
\hline $\begin{array}{l}\text { Multi-dimensional pinch analysis (or) } \\
\text { Multi-objective pinch analysis } \\
\{\text { Composite Quality Index }\}\end{array}$ & $\begin{array}{l}\text { Jia X, et al. [47] } \\
\text { Priya, et al. [22] } \\
\text { Priya \& Bandyopadhyay [20], [21] } \\
\{\text { Patole, et al. [10], [17]\} }\end{array}$ \\
\hline Opportunity cost targeting algorithm & $\begin{array}{l}\text { Bandyopadhyay \& Desai [39], } \\
\text { Roychaudhari \& Bandopadhyay[97] }\end{array}$ \\
\hline $\begin{array}{l}\text { Outsourced and storage electricity } \\
\text { curves }\end{array}$ & Wan Almi, et al.[37] \\
\hline $\begin{array}{l}\text { Standalone hybrid power pinch } \\
\text { analysis (SAHPPA) }\end{array}$ & $\begin{array}{l}\text { Ho, et al.[44], Norbu \& } \\
\text { Bandyopadhyay[45] }\end{array}$ \\
\hline $\begin{array}{l}\text { T-T graphical representation of hot } \\
\text { and cold composite curves, instead of } \\
\text { the conventional T-H diagram }\end{array}$ & Gadalla [109], [110], [111] \\
\hline $\begin{array}{l}\text { Water footprint pinch analysis } \\
\text { (WFPA) }\end{array}$ & Tan RR. et al.[63] \\
\hline
\end{tabular}

The use of pinch analysis to optimise the storage capacity needed for electricity generated from renewable sources of energy like wind and solar, as shown in Ghosh et al.$^{[46]}$ is a shot in the arm for this technique, considering that the need to store electricity has often been a hurdle in the rapid development of renewable energy installations. Pinch analysis applied for site-wide integration will help more and more industrial units in the future to conceive a symbiotic network among themselves, which proves to be beneficial to all of them. Of course, absence of cooperation for mutual benefits, will be a hurdle to the implementation of pinch analysis recommendations.

\subsection{Weaknesses}

Steinmeyer ${ }^{[8]}$ had expressed concern that pinch analysis, by narrowing down the focus, may miss out on major opportunities for improvement in other words, it may miss the wood for the trees, to cull a metaphor. While that was over 25 years ago, things have changed en route. However, one ought to be aware of the risk of this weakness creeping in, if researchers tend to miss the bigger picture. Pinch analysis, obviously, has its own set of limitations, as Thasai \& Siemanond ${ }^{[57]}$ for instance have pointed out. But that has been overcome. In order to obtain information about possibilities of holistic energy saving both heat and work pinch analysis needs to be combined with exergy analysis in what then becomes CPEA. One may wish to look upon this limitation as a weakness of pinch analysis, or as an opportunity to combine it with other analysis methods to expand the scope of the study.

\subsection{Opportunities}

The weakness pointed out in Steinmeyer ${ }^{[8]}$ has been effectively overcome by researchers who have developed the so-called multi-objective pinch analysis, where focus on one issue then gives away or in fact, forms the bedrock on other issues like Patole et al. ${ }^{[10]}$ who have started off with a CEPA, and then extended the results to look at the water footprint, land footprint etc. Utilising this opportunity will entrench pinch analysis as a holistic sustainability analysis tool in the future. With the reduction of GHG emissions already a priority in countries like India and China, the power of CEPA in aiding decision-making ${ }^{[19,25]}$ can be harnessed to good effect. As already mentioned in the previous sub-section, the possibility to combine pinch analysis with other tools (like exergy analysis in CPEA), can be considered as an opportunity.

\subsection{Threats}

It is worth mentioning here that thermal pinch analysis, contrary to another tool called bridge analysis, does not provide detailed information about the modifications which need to be done to the network. This may make some researchers prefer the latter to the former. This observation was made in a publication originating from the developed world, but this author thought that it deserved mention as a threat to pinch analysis.

\section{Conclusions and recommendations}

Only those publications which have 'pinch analysis' in their titles have been read and reviewed in this paper. That of course is a key limitation, as there obviously are pinch-analysis-based publications where the term may appear in the Abstract and/or the Keywords, but not the Article Title. The author is aware of this limitation but also believe that this 'narrowing down' process has made this particular paper more compact and of reasonable length. Further, only Scopus has been availed of as the repository of publications, on the basic premise that it is a well-known fact that Scopus is the largest database in vogue (encompassing over 14,000 journal titles), and thereby there is a likelihood of most (if not all) publications related to known fields of research like pinch analysis, being accessible through it. Of course, there may be some journals and thereby publications which may tend to get left out, but this would be a negligibly small fraction. Further, on a very valid premise outlined earlier, 
only those publications focusing on case studies from the developing world and transition economies have been considered eventually for a more detailed critique.

Table 1 gives a brief summary of the methods which can be considered as offshoots or complements or extensions of the traditional form of pinch analysis, with examples of some of the publications which have introduced or applied them in the case studies. The resources focused on, include heat and electricity, water (and wastewater), solid wastes, land (surface area), storage space (volume), time, human resources (labour), mass of resources in general, hydrogen and greenhouse gases (as a resource with a negative value). The socioeconomic sectors encompassed in the review include the power sector (which clearly dominates), oil and gas, biofuels, paper and pulp, chemical and petrochemical, water supply and wastewater treatment, food and transportation.

It is worth mentioning at this juncture, that there may be other fields of application of pinch analysis for optimisation of one or more of the resources depicted in Figure 4, which may have been inadvertently left out by the author in this review paper. It would suffice to say that pinch analysis is well-poised, after a long learning curve, to be applied to practically any sector of the global economy, to optimise the consumption of any resource material or non-material, biotic or abiotic, stock, fund or flow.

As seen, over time, the methodology has evolved thanks to researchers from across the world, and has been applied to optimise the use of a range of resources in a wide variety of industrial sectors and urban utilities. If the focus is narrowed down to the years 2017 and 2018 for instance (and all publications from both developed and developing countries are considered), the diversity of applications is conspicuous breweries, transportation, economy-wide analysis, biofuels, food, chemicals, paper $\&$ pulp and brick (with 1 publication each); water \& sanitation, sugar and cement ( 2 each), and solid waste management (with 3 publications). It was in 2018 that Opportunity Cost Targeting Algorithm was introduced as a pinch-analysis offshoot and a year before that, Financial Pinch Analysis was developed and applied (Refer Table 1). Of late, multi-dimensional pinch analysis (Refer Table 1) where several resources are optimised at the same time - is being mooted as a powerful and effective sustainability tool which holds great potential in the future.

To sum up, pinch analysis has entrenched itself alongwith many other methods environmental life-cycle analysis (E-LCA), social-LCA, material flow analysis (MFA) and life-cycle costing analysis (LCCA) to name a few as a powerful tool in the sustainable-development toolkit.

\section{Acknowledgements}

The author would like to thank Prof. Lars Nilsson of Karlstad University for his comments, which were useful in improving this paper.

\section{References}

[1] United Nations, 2015. World population projected to reach 9.7 billion by 2050 . Accessed at http://www.un.org/en/development/desa/news/population/ 2015-report.html

[2] Meadows DH, Meadows DL, Randers J, et al. The Limits to Growth; A Report for the Club of Rome's Project on the Predicament of Mankind, 1972, New York: Universe Books. ISBN 0876631650. https://doi.org/10.1349/ddlp.1

[3] Linhoff B. Thermodynamic Analysis in the Design of Process Networks, PhD thesis, 1979, University of Leeds, United Kingdom.

[4] Boland D and Linhoff B. The preliminary design of networks for heat exchange by systematic methods, Chemical Engineering, 1979, 9-15. https://doi.org/10.1016/j.coche.2013.10.003

[5] Kleme JJ and Kravanja Z. Forty years of Heat Integration: Pinch Analysis (PA) and Mathematical Programming (MP). Current Opinion in Chemical Engineering, 2013, 2(4): 461474.

[6] Kemp I. Pinch Analysis and Process Integration. A user guide on process integration for the efficient use of energy, 2006, Pages 416. Published by Butterworth-Heinemann, United Kingdom. ISBN 9780750682602.

[7] Morgan S. Use process integration to improve process designs and the design process. Chemical Engineering Progress, 1992, 62-68.

[8] Steinmeyer D. Save energy, without entropy. HydroCarb Process, 1992, 71: 55-95.

[9] Tan RR, Bandyopadhyay S, Foo DCY, et al. Prospects for novel Pinch Analysis application domains in the 21st century. Chemical Engineering Transactions, 2015, 45: 17411746.

[10] Patole M, Tan RR, Bandyopadhyay S, et al. Pinch analysis approach to energy planning using weighted composite quality index. Chemical Engineering Transactions, 2016, 52: 961-966.

[11] Rozali NEM, Alwi SRW, Ho WS, et al. Expansion of a diesel plant into a hybrid power system using power pinch analysis. Chemical Engineering Transactions, 2015A, 45: 343-348.

[12] Rozali NEM, Tin OS, Wan Alwi SR, et al. Electricity Load Reduction in Hybrid Power Systems Using Power Pinch Analysis. Computer-aided Chemical Engineering, 2014, 33: 1495-1500.

https://doi.org/10.1016/B978-0-444-63455-9.50084-2

[13] Rozali NEM, Wan Alwi SR, Ho WS, et al. Integration of diesel plant into a hybrid power system using power pinch analysis. Applied Thermal Engineering, 2016A, 105: 792798.

https://doi.org/10.1016/j.applthermaleng.2016.05.035 
[14] Rozali NEM, Wan Alwi SR, Manan ZA, et al. Peak-offpeak load shifting for hybrid power systems based on Power Pinch Analysis. Energy, 2015B, 90: 128-136. https://doi.org/10.1016/j.energy.2015.05.010

[15] Rozali NEM, Wan Alwi SR, Manan ZA, et al. Sensitivity analysis of hybrid power systems using Power Pinch Analysis considering Feed-in Tariff. Energy, 2016B, 116: 12601268 .

https://doi.org/10.1016/j.energy.2016.08.063

[16] Rozali NEM, Zaki SAASM, Ho WS, et al. Study of the effects of peak/off-peak load shifting on hybrid power system storage using Power Pinch Analysis. Chemical Engineering Transactions, 2017, 61: 1519-1524.

[17] Patole M, Bandyopadhyay S, Foo DCY, et al. Energy sector planning using multiple-index pinch analysis. Clean Technologies and Environmental Policy, 2017, 19(7): 19671975. https://doi.org/10.1007/s10098-017-1365-6

[18] Priya GSK and Bandyopadhyay S. A Pinch Analysis based approach to power system planning with carbon capture. Chemical Engineering Transactions, 2015A, 1603-1608.

[19] Priya GSK and Bandyopadhyay S. Emission constrained power system planning: A pinch analysis based study of Indian electricity sector. Clean Technologies and Environmental Policy, 2013, 15(5): 771-782. https://doi.org/10.1007/s10098-012-0541-y

[20] Priya GSK and Bandyopadhyay S. Multi-objective pinch analysis for power system planning. Applied Energy, 2017B, 202: 335-347. https://doi.org/10.1016/j.apenergy.2017.05.137

[21] Priya GSK and Bandyopadhyay S. Multiple objectives Pinch Analysis. Resources, Conservation and Recycling, 2017A, 119: 128-141. https://doi.org/10.1016/j.resconrec.2016.02.005

[22] Priya GSK, Bandyopadhyay S and Tan RR. Multi-objective pinch analysis with multiple resources. Chemical Engineering Transactions, 2015B, 45: 823-828.

[23] US Energy Information Administration, 2017. Chinese coal-fired electricity generation expected to flatten as mix shifts to renewables. Available at: https://www.eia.gov/todayinenergy/detail.php?id=33092. Accessed on www.eia.gov, on 18-09-2018.

[24] International Energy Agency, 2015. India Energy Outlook World Energy Outlook Special Report. Accessible at: https://www.iea.org/publications/freepublications/ publication/IndiaEnergyOutlook_WEO2015.pdf. cessed on 18-09-2018.

[25] Li Z, Jia X, Foo DCY, et al. Minimizing carbon footprint using pinch analysis: The case of regional renewable electricity planning in China. Applied Energy, 2016, 184: 10511062. https://doi.org/10.1016/j.apenergy.2016.05.031

[26] Ataei A and Yoo C. Combined pinch and exergy analysis for energy efficiency optimization in a steam power plant. International Journal of Physical Sciences, 2010, 5(7): 11101123.

[27] Farhad S, Saffar-Avval M and Younessi-Sinaki M. Efficient design of feedwater heaters network in steam power plants using pinch technology and exergy analysis. International Journal of Energy Research, 2008, 32(1): 1-11. https://doi.org/10.1002/er.1319
[28] Tan RR, Sum Ng DK and Yee Foo DC. Pinch analysis approach to carbon-constrained planning for sustainable power generation. Journal of Cleaner Production, 2009, 17(10): 940-944. https://doi.org/10.1016/j.jclepro.2009.02.007

[29] Wang Z, Wang C, Li Q, et al. Pinch analysis of CO2 capture in power plant and process integration energy saving. Huagong Xuebao/CIESC Journal, 2012, 63(2): 593-598.

[30] Ooi REH, Foo DCY, Ng DKS, et al. Planning of carbon capture and storage with pinch analysis techniques. Chemical Engineering Research and Design, 2013, 91(12): 27212731. https://doi.org/10.1016/j.cherd.2013.04.007

[31] Zhang K, Liu Z, Huang S, et al. Process integration analysis and improved options for an MEA carbon dioxide capture system based on the pinch analysis. Applied Thermal Engineering, 2015, 85: 214-224. https://doi.org/10.1016/j.applthermaleng.2015.03.073

[32] Valiani S, Tahouni N and Panjeshahi MH. Optimization of pre-combustion capture for thermal power plants using Pinch Analysis. Energy, 2017, 119: 950-960. https://doi.org/10.1016/j.energy.2016.11.046

[33] Asl SS, Tahouni N and Panjeshahi MH. Energy benchmarking of thermal power plants using pinch analysis. Journal of Cleaner Production, 2018, 171: 1342-1352. https://doi.org/10.1016/j.jclepro.2017.10.021

[34] Khoshgoftar Manesh MH and Rosen MA. Combined Cycle and Steam Gas-Fired Power Plant Analysis through Exergoeconomic and Extended Combined Pinch and Exergy Methods. Journal of Energy Engineering, 2018, 144(2): Article number 4018010. https://doi.org/10.1061/(ASCE)EY.1943-7897.0000506

[35] Gadalla M, Emun F, Majozi T, et al. Environmental Design of IGCC through Pinch Analysis, Process Integration and Parameters Analysis. Computer-Aided Chemical Engineering, 2009, 26: 561-566. https://doi.org/10.1016/S1570-7946(09)70094-X

[36] Arriola-Medelln A, Manzanares-Papayanopoulos E and Romo-Millares C. Diagnosis and redesign of power plants using combined Pinch and Exergy Analysis. Energy, 2014, 72: 643-651. https://doi.org/10.1016/j.energy.2014.05.090

[37] Wan Alwi SR, Tin OS, Rozali NEM, et al. New graphical tools for process changes via load shifting for hybrid power systems based on Power Pinch Analysis. Clean Technologies and Environmental Policy, 2013, 15(3): 459-472. https://doi.org/10.1007/s10098-013-0605-7

[38] Lee MY, Ho WS, Hashim H, et al. Sustainable power plant planning using pinch analysis approach. Chemical Engineering Transactions, 2015, 45: 673-678.

[39] Bandyopadhyay S and Desai NB. Cost optimal energy sector planning: a Pinch Analysis approach. Journal of Cleaner Production, 2016, 136: 246-253. https://doi.org/10.1016/j.jclepro.2016.03.077

[40] Liu WH, Kaliappan K, Alwi SRW, et al. Power Pinch Analysis supply side management: strategy on purchasing and selling of electricity. Clean Technologies and Environmental Policy, 2016, 18(8): 2401-2418. https://doi.org/10.1007/s10098-016-1213-0 
[41] Guo C, Du X, Yang L and Yang Y. Performance analysis of organic Rankine cycle based on location of heat transfer pinch point in evaporator. Applied Thermal Engineering, 2014, 62(1): 176-186. https://doi.org/10.1016/j.applthermaleng.2013.09.036

[42] Wu SY, Zhou SM and Xiao L. The determination and matching analysis of pinch point temperature difference in evaporator and condenser of organic Rankine cycle for mixed working fluid. International Journal of Green Energy, 2016, 13(5): 470-480. https://doi.org/10.1080/15435075.2014.966371

[43] Sarkar J. A Novel Pinch Point Design Methodology Based Energy and Economic Analyses of Organic Rankine Cycle. Journal of Energy Resources Technology, Transactions of the ASME, 2018, 140(5): Article number 52004. https://doi.org/10.1115/1.4038963

[44] Ho WS, Khor CS, Hashim H,et al. SAHPPA: A novel power pinch analysis approach for the design of off-grid hybrid energy systems Clean Technologies and Environmental Policy, 2014, 165: 957-970.

https://doi.org/10.1007/s10098-013-0700-9

[45] Norbu S and Bandyopadhyay S. Power Pinch Analysis for optimal sizing of renewable-based isolated system with uncertainties. Energy, 2017, 135: 466-475. https://doi.org/10.1016/j.energy.2017.06.147

[46] Ghosh PC, Bandyopadhyay S and Krishnapriya GS. Design space approach for storage sizing of hydrogen fuel cell systems through pinch analysis. Chemical Engineering Transactions, 2015, 45: 1105-1110.

[47] Jia X, Li Z, Wang F, et al. Multi-dimensional pinch analysis for sustainable power generation sector planning in China. Journal of Cleaner Production, 2016, 112: 2756-2771. https://doi.org/10.1016/j.jclepro.2015.10.102

[48] Zhang Q, Yang X and Yu S. Pinch-point analysis of refinery hydrogen networks and optimization. Petroleum Refinery Engineering, 2012, 42(11):1-5.

[49] Huang FL, Liu LY, Liu JR, et al. Pinch analysis and optimization of hydrogen network. Huaxue Gongcheng / Chemical Engineering (China), 2013, 41(7): 69-73.

[50] Zhang Q, Yang M, Liu G, et al. Relative concentration based pinch analysis for targeting and design of hydrogen and water networks with single contaminant. Journal of Cleaner Production, 2016, 112: 4799-4814. https://doi.org/10.1016/j.jclepro.2015.06.019

[51] China Strategic Research, 2017. China's Fuel Cells Market is a Long Way off. Accessed at: http://www.gcis.com.cn/china-insights/industry-articles/ 143-china-s-fuel-cells-market-is-a-long-way-off, on 21st September 2018.

[52] The Teheran Times, 2016. Water crisis in Iran: A desperate call for action. Accessed at https://www.tehrantimes.com/news/301198/

Water-crisis-in-Iran-A-desperate-call-for-action, on 23rd September

[53] Bidhendi Nabi GR, Mehrdadi N and Mohammadnejad S. Water and wastewater minimization in Tehran oil refinery using water pinch analysis. International Journal of Environmental Research, 2010, 4(4): 583-594.
[54] Mohammadnejad S, Ataei A, Bidhendi GRN, et al. Water pinch analysis for water and wastewater minimization in Tehran oil refinery considering three contaminants. Environmental Monitoring and Assessment, 2012, 184(5): 2709-2728.

https://doi.org/10.1007/s10661-011-2146-z

[55] Mohammadnejad S, Bidhendi GRN and Mehrdadi N. Water pinch analysis in oil refinery using regeneration reuse and recycling consideration. Desalination, 2011, 265: 255-265. https://doi.org/10.1016/j.desal.2010.07.059

[56] Ghorbani B, Salehi GR, Ghaemmaleki H, et al. Simulation and optimization of refrigeration cycle in NGL recovery plants with exergy-pinch analysis. Journal of Natural Gas Science and Engineering, 2012, 7: 35-43. https://doi.org/10.1016/j.jngse.2012.03.003

[57] Thasai J and Siemanond K. Combined exergy-pinch analysis to improve cryogenic process. Chemical Engineering Transactions, 2015, 43: 1435-1440.

[58] Beninca M, Trierweiler JO and Secchi AR. Heat integration of an olefins plant: Pinch analysis and mathematical optimization working together. Brazilian Journal of Chemical Engineering, 2011, 28(1): 101-116. https://doi.org/10.1590/S0104-66322011000100013

[59] Zhao D, Xue J, Li S, et al. Optimizing low-temperature heat recovery in a refinery fluid catalytic cracking unit based on pinch analysis. China Petroleum Processing and Petrochemical Technology, 2012, 14(2): 82-88.

[60] Cui C and Sun J. Coupling design of inter-unit heat integration in an industrial crude distillation plant using pinch analysis. Applied Thermal Engineering, 2017, 117: 145-154. https://doi.org/10.1016/j.applthermaleng.2017.02.032

[61] Angsutorn N, Siemanond K and Chuvaree R. Heat exchanger network synthesis using MINLP Stage-wise model with pinch analysis and relaxation. Computer-Aided Chemical Engineering, 2014, 33: 139-144. https://doi.org/10.1016/B978-0-444-63456-6.50024-7

[62] Diamante JAR, Tan RR, Foo DCY, et al. A graphical approach for pinch-based source-sink matching and sensitivity analysis in carbon capture and storage systems. Industrial and Engineering Chemistry Research, 2013, 52(22): 72117222 .

https://doi.org/10.1021/ie302481h

[63] Tan RR, Foo DCY, Aviso KB, et al. The use of graphical pinch analysis for visualizing water footprint constraints in biofuel production. Applied Energy, 2009, 86(5): 605-609. https://doi.org/10.1016/j.apenergy.2008.10.004

[64] Palacios-Bereche R, Ensinas AV, Modesto M, et al. Mechanical vapour recompression incorporated to the ethanol production from sugarcane and thermal integration to the overall process applying pinch analysis. Chemical Engineering Transactions, 2014, 39: 397-402.

[65] Petersen AM, Melamu R, Knoetze JH, et al. Comparison of second-generation processes for the conversion of sugarcane bagasse to liquid biofuels in terms of energy efficiency, pinch point analysis and Life Cycle Analysis. Energy Conversion and Management, 2015, 91: 292-301. https://doi.org/10.1016/j.enconman.2014.12.002 
[66] Snchez E, Ojeda K, El-Halwagi M, et al. Biodiesel from microalgae oil production in two sequential esterification/transesterification reactors: Pinch analysis of heat integration. Chemical Engineering Journal, 2011, 176-177: 211-216. https://doi.org/10.1016/j.cej.2011.07.001

[67] Jia Z, Chi R, Sun L, et al. Biodiesel processes energy improvement based on Pinch and exergy Analysis. Chemical Engineering Transactions, 2017, 61: 487-492.

[68] Yang JK, Feng X and Yu XJ. Sub-system selection and application in pinch analysis. Huaxue Gongcheng/Chemical Engineering (China), 2009, 37(3): 70-74.

[69] Foo DCY. State-of-the-art review of pinch analysis techniques for Water Network synthesis. Industrial and Engineering Chemistry Research, 2009, 48(11): 5125-5159. https://doi.org/10.1021/ie801264c

[70] Wang F, Gao Y, Dong W, et al. Segmented pinch analysis for environmental risk management. Resources, Conservation and Recycling, 2017, 122: 353-361. https://doi.org/10.1016/j.resconrec.2017.03.010

[71] Tan RR, Aziz MKA, Ng DKS, et al. Pinch analysis-based approach to industrial safety risk and environmental management. Clean Technologies and Environmental Policy, 2016, 18(7): 2107-2117. https://doi.org/10.1007/s10098-016-1101-7

[72] Qin Z, Tang K, Wu X, et al. Product-based Carbon Constraint Energy Planning with pinch analysis for sustainable methanol industry in China. Chemical Engineering Transactions, 2017, 61: 103-108.

[73] Jia X, Li Z, Wang F, et al. A new graphical representation of water footprint pinch analysis for chemical processes. Clean Technologies and Environmental Policy, 2015, 17(7): 19871995. https://doi.org/10.1007/s10098-015-0921-1

[74] Jia XP, Liu CH and Qian Y. Carbon emission pinch analysis for energy planning in chemical industrial park. Xiandai Huagong/Modern Chemical Industry, 2009, 29(9): 81-85.

[75] Yu YS, Li Y, Lu HF, et al. Synergy pinch analysis of CO2 desorption process. Industrial and Engineering Chemistry Research, 2011, 50(24): 1399714007. https://doi.org/10.1021/ie2004847

[76] Li Q, Ji ZL, Zhang DY, et al. Pinch analysis on the heat exchanger network of the triethylene glycol (TEG) dehydration unit in gas purification plants. Natural Gas Industry, 2009, 29(10): 104-106. https://doi.org/10.1016/S1003-9953(08)60072-9

[77] Ghannadzadeh A and Sadeqzadeh M. Exergy aided pinch analysis to enhance energy integration towards environmental sustainability in a chlorine-caustic soda production process. Applied Thermal Engineering, 2017A, 125: 15181529. https://doi.org/10.1016/j.applthermaleng.2017.07.052

[78] Ghannadzadeh A and Sadeqzadeh M. Combined pinch and exergy analysis of an ethylene oxide production process to boost energy efficiency toward environmental sustainability. Clean Technologies and Environmental Policy, 2017B, 19(8): 2145-2160. https://doi.org/10.1007/s10098-017-1402-5

[79] Rao NK. Pinch analysis of acrylic acid process plant. International Journal of Chemtech Research, 2016, 9(6): 432439.
[80] Ma GJ, Li AH, Liu JH, et al. Pinch analysis for heat exchanger network of solvent recovery system for a butanonetoluene dewaxing process. Xiandai Huagong/Modern Chemical Industry, 2016, 36(4): 163-166.

[81] Balla WH, Rabah AA and Abdallah BK. Pinch Analysis of Sugarcane Refinery Water Integration. Sugar Tech, 2018, 202: $122-134$. https://doi.org/10.1007/s12355-017-0535-5

[82] Hou S. Two-stage solar multi-effect humidification dehumidification desalination process plotted from pinch analysis. Desalination, 2008, 222: 572-578. https://doi.org/10.1016/j.desal.2007.01.127

[83] Esfahani JI and Yoo C. An optimization algorithmbased pinch analysis and GA for an off-grid batteryless photovoltaic-powered reverse osmosis desalination system. Renewable Energy, 2016, 91(C): 233-248. https://doi.org/10.1016/j.renene.2016.01.049

[84] Kang H, Wang T and Zheng H. Comparative analysis of regenerative and air-extraction multi-stage humidificationdehumidification desalination system using pinch technology. Desalination, 2016, 385: 158-166. https://doi.org/10.1016/j.desal.2016.02.012

[85] Li Y, Zhou JT and Yao PJ. Optimal design of wastewater treatment networks by combination of water pinch analysis and mathematical programming. Dalian Ligong Daxue Xuebao/Journal of Dalian University of Technology, 2010, 50(1): $38-41$.

[86] Liang Z, Li Y, Liu M, et al. Design of Water-Using Network with Single Internal Water Main Based on Water Pinch Analysis. Hsi-An Chiao Tung Ta Hsueh/Journal of Xi' an Jiaotong University, 2017, 51(4): 149-154.

[87] Kim M, Kim MJ, Pyo SH, et al. Greenhouse gas emission pinch analysis (GEPA) for evaluation of emission reduction strategies. Clean Technologies and Environmental Policy, 2016, 18(5): 1381-1389. https://doi.org/10.1007/s10098-015-1063-1

[88] Ramli AF, Muis ZA and Ho WS. Carbon emission pinch analysis: An application to transportation sector in Iskandar Malaysia 2025. Chemical Engineering Transactions, 2017, 56: $343-348$ https://doi.org/10.1007/s10098-018-1579-2

[89] Tan ST, Ho WS, Hashim H, et al. Waste Management Pinch Analysis (WAMPA) with economic assessment. Chemical Engineering, 2015, 45: 145-150.

[90] Jia X, Wang S, Li Z, et al. Pinch analysis of GHG mitigation strategies for municipal solid waste management: A case study on Qingdao City. Journal of Cleaner Production, 2018, 174: 933-944. https://doi.org/10.1016/j.jclepro.2017.10.274

[91] Othman KI, Lim JS, Ho WS, et al. Carbon emission pinch analysis for sustainable landfill. Chemical Engineering Transactions, 2017, 56: 517-522.

[92] Ho WS, Hashim H, Lim JS, et al. Waste Management Pinch Analysis (WAMPA): Application of Pinch Analysis for greenhouse gas (GHG) emission reduction in municipal solid waste management. Applied Energy, 2017, 185: 14811489.

https://doi.org/10.1016/j.apenergy.2016.01.044 
[93] Li YG, Liu HB, Tao JS, et al. Optimizational analysis of heat-recovery in drying-section of coating machine based on pinch technology. Zhongguo Zaozhi Xuebao/Transactions of China Pulp and Paper, 2018, 25(2): 71-75.

[94] Jabbari B, Tahouni N, Ataei A, et al. Design and optimization of CCHP system incorporated into kraft process, using Pinch Analysis with pressure drop consideration. Applied Thermal Engineering, 2013, 61(1): 88-97. https://doi.org/10.1016/j.applthermaleng.2013.01.050

[95] Bakhtiari B, Pylkkanen V and Retsina T. Pinch analysis An essential tool for energy optimisation of pulp and paper mills. O Papel. 76(4): 51-54.

[96] Roychaudhari PS, Kazantzi V, Foo DCY, et al. Selection of energy conservation projects through Financial Pinch Analysis. Energy, 2017, 138: 602-615. https://doi.org/10.1016/j.energy.2017.07.082

[97] Roychaudhari PS and Bandyopadhyay S. Financial Pinch Analysis: Minimum opportunity cost targeting algorithm. Journal of Environmental Management, 2018, 212: 88-98. https://doi.org/10.1016/j.jenvman.2018.02.005

[98] Tan RR, Aviso KB and Foo DCY. Economy-wide carbon emissions pinch analysis. Chemical Engineering Transactions, 2017, 61: 913-918.

[99] Abdul Aziz E, Wan Alwi SR, Lim JS, et al. An integrated Pinch Analysis framework for low carbon dioxide emissions industrial site planning. Journal of Cleaner Production, 2017, 146: 125-138. https://doi.org/10.1016/j.jclepro.2016.07.175

[100] Mohd Nawi WNR, Wan Alwi SR, Manan ZA, et al. A new algebraic pinch analysis tool for optimising carbon dioxide capture, utilisation and storage. Chemical Engineering Transactions, 2015, 45: 265-270.

[101] Mohd Nawi WNR, Wan Alwi SR, Manan ZA, et al. Pinch Analysis targeting for carbon dioxide Total Site planning. Clean Technologies and Environmental Policy, 2016, 18(7): 2227-2240. https://doi.org/10.1007/s10098-016-1154-7

[102] Bandyopadhyay S. Mathematical foundation of Pinch Analysis. Chemical Engineering Transactions, 2015, 45: 1753-1758.

[103] Dimian AC, Bildea CS and Kiss AA. Pinch Point Analysis. Computer-Aided Chemical Engineering, 2014, 33: 525564.

https://doi.org/10.1016/B978-0-444-62700-1.00013-9
[104] Li BH and Chang CT. Retrofitting heat exchanger networks based on simple pinch analysis. Industrial and Engineering Chemistry Research, 2010, 49(8): 3967-3971. https://doi.org/10.1021/ie9016607

[105] Sun L, Zhao Y and Luo X. Minimum temperature difference analysis and pinch technology of multi-tube heat exchanger networks. Huagong Xuebao/CIESC Journal, 2012, 63(9): 2991-2999.

[106] Tewari K, Agrawal S and Kumar Arya R. Generalized Pinch Analysis Scheme Using MATLAB. Chemical Engineering and Technology, 2015, 38(3): 530-536. https://doi.org/10.1002/ceat.201400475

[107] Luo X, Sun L, Wang C, et al. Operating pinch point analysis and bypass optimal control of heat exchanger networks. Huagong Xuebao/Journal of Chemical Industry and Engineering (China), 2008, 59(5):1200-1206.

[108] Chaturvedi ND and Bandyopadhyay S. Minimization of storage requirement in a batch process using pinch analysis. Computer Aided Chemical Engineering, 2012, 31: 670674. https://doi.org/10.1016/B978-0-444-59507-2.50126-8

[109] Gadalla MA. A new graphical method for Pinch Analysis applications: Heat exchanger network. Energy, 2015A, 81: 159-174. https://doi.org/10.1016/j.energy.2014.12.011

[110] Gadalla MA. A novel graphical technique for Pinch Analysis. Energy Conversion and Management, 2015B, 96: 499510. https://doi.org/10.1016/j.enconman.2015.02.079

[111] Gadalla MA. A new graphical method for pinch analysis and energy integration. Chemical Engineering Transactions, 2015C, 43: 1291-1296.

[112] Foo DCY, Hallale N and Tan RR. Optimise shift-scheduling using pinch analysis. Chemical Engineering, 2010, 117(7): 48-52

[113] Sun WT and Hu YS. Solution and analysis of the operating pinch point in heat exchanger networks. Petrochemical Equipment, 2010, 39(2): 18-22.

[114] Bonhivers JC, Svensson E, Berntsson T, et al. Comparison between pinch analysis and bridge analysis to retrofit the heat exchanger network of a kraft pulp mill. Applied Thermal Engineering, 2014, 70(1): 369-379.

https://doi.org/10.1016/j.applthermaleng.2014.04.052 